\title{
Optimising Cancer Surgery During COVID-19: Experience of Tertiary Cancer Centre in Eastern India
}

\author{
Rekha Das ${ }^{1}$ (1) - Snigdha Rani Nahak ${ }^{2} \cdot$ Jita Parija $^{3} \cdot$ Prafulla K. Das $^{4} \cdot$ Lalatendu Sarangi $^{5}$ • \\ Padmalaya Devi ${ }^{4} \cdot$ Pramod C. Pathy $^{6}$
}

Received: 19 November 2020 / Revised: 11 January 2021 / Accepted: 13 January 2021 / Published online: 26 March 2021

(C) Association of Gynecologic Oncologists of India 2021

\begin{abstract}
Purpose The timely management of cancer surgery suffered due to COVID-19 and nationwide lockdown. Continuing cancer surgery was a challenge faced by all. We present our experience on cancer surgery in a cancer centre with high volume of patients and limited resources during early pandemic.

Methods We retrospectively analysed our operation theatre database on surgery and anaesthesia from 1st April to 30th June 2020.

Results A total of 457 surgeries were done-complex major, major, intermediate and minor surgeries constituted $43 \%$, $25 \%, 12 \%$ and $20 \%$, respectively. Median age of patient was 50 years, and $76 \%$ were below 60 . The median ASA class was I (I-IV), and 97\% were ASA I and II. The median Eastern Cooperative Oncology Group score was 0 (0-3), and 92\% had score 0 and 1 . Major cases done under regional anaesthesia were $30.7 \%$. Median length of intensive care unit stay was 1 (1-6) days, and length of hospital stay was 7 (7-15) days. Clavien-Dindo Grade II complication in patients above 60 years was $16.4 \%$ and below 60 years was $17.6 \%(p=0.76) .10 \%$ in ASA I compared to $26 \%$ of ASA II $(p=0.00)$ and $15.9 \%$ with ECOG 0 and 1 compared to $30.9 \%$ with ECOG 3 and $4(p=0.01)$ had grade II complication. Four (1\%) patients had Grade $\geq$ III CD complication. Covid testing was undertaken in 52\% patients pre-operatively, and there was no positive case in post-operative period.

Conclusions Adopting and implementing institutional policy catering to limited resource available at our centre, we facilitated cancer surgery.
\end{abstract}

Keywords COVID-19 $\cdot$ Cancer surgery $\cdot$ Limited resource $\cdot$ Institutional policy $\cdot$ Complications

\section{Introduction}

Early delivery of cancer treatment is a priority in cancer centre; its timely management became an overriding burden in cancer hospitals during the COVID-19 pandemic. The sudden nationwide lockdown resulted in utter confusion in the management of cancer patients, more so for patients requiring surgery [1]. Early-stage diseases were worst affected. The patients were eager to undergo the procedure with the notion "Covid may not be fatal, but cancer will be". But the media coverage instilled fear amongst the service care providers and the general public at large, on the large scale morbidity \& mortality associated with the Covid infection, although in good faith. The tests for Covid were not freely available , and the test was customised as per the demand supply situation. The ICMR guidelines were pretty conservative, testing limited to symptomatic cases only. But in AHPGIC/Cuttack, the only public sector cancer hospital in Odisha and an important tertiary cancer centre in eastern India, we could not afford to stop cancer surgeries altogether; it was scaled down. In the absence of a national guideline, Government of Odisha permitted us to go for tests in a limited manner for patients scheduled for radical procedures with doubtful symptoms for Covid. This guided us to formulate our policy so that we could continue cancer surgery in controlled manner. 


\section{Aim}

We aimed to analyse our experience with surgical procedures undertaken at our centre and their outcome during early COVID-19 pandemic.

\section{Methodology}

We performed a retrospective analysis of operation theatre (OT) procedures conducted and anaesthesia administered to patients who underwent surgery in our tertiary cancer hospital from 1st April to 30th June 2020.

Selection criteria of patients planned for surgery were based on predictive operative risk and other criteria evaluated during pre-anaesthetic check-up. They were

\section{Disease Criteria}

1. Early stage where surgery will offer potential cure.

2. Selected debulking surgery-cytoreductive and palliative surgery.

3. Patients already admitted.

4. Surgery duration $<6 \mathrm{~h}$.

5. All emergency procedures-e.g. gastric outlet obstruction, perforation, bleeding, tracheostomy.

\section{Patient Criteria}

1. Younger age (age less than 40 years).

2. Patients with good performance score (ECOG grade 0 and 1).

3. Patients with good physical status (ASA I and II).

4. Optimisation duration $<72 \mathrm{~h}$.

\section{Other Factors}

1. Assured availability of blood and blood products, medications and surgical materials.

2. Assured selected surgical team, allotted OT table and time-by limiting rescheduling and resequencing.

3. Safe anaesthesia practice and preference to regional anaesthesia.

Procedures avoided were:

Lung function test and spirometry that require repeated forceful exhalation manoeuvres.

Those associated with prolonged post-operative stay.

Massive resections and bloody surgeries associated with excessive energy source.

Laparoscopic surgeries and endoscopic procedures.
Hospital adopted various measures like stringent screening procedures, adhering to safety measures like social distancing, hand hygiene, wearing mask and restricting to one attendant in hospital premises, optimising the pre-operative workup and adopting safe anaesthesia and surgical practice to prevent COVID-19 infection to patients, healthcare providers and fellow patients while maximising the turnover and positive patients outcome. COVID-19 testing was available in our Institute after 23rd April in limited numbers, so standard precautions for Covid were undertaken for all OT cases.

All surgical procedures undertaken between 1st April to 30th June were evaluated for total number of cases done, the type, age of patient, ASA, ECOG grade, types of surgery, surgical complexity, method of anaesthesia, postoperative ICU stay (ICUS), total length of hospital stay (TLHS) and morbidity and mortality. Although we do not routinely take up paediatric surgical cases, a few surgeries were stretched out to these age groups due to non-availability of surgical services in other places.

\section{Statistical Analysis}

We maintain a database in OT of all surgical and anaesthesia parameters. The statistical data were analysed using IBM SPSS version 23, for windows 2010 (IBM Corp; Armonk, N.Y; USA). Continuous nonparametric variables were expressed as median with range and normal distribution as mean with standard deviation. Categorical values were expressed as frequencies and percentages. For the comparison of proportions of patients with CD grade II complication, by age group, American Society of Anaesthesiology (ASA) and Eastern Cooperative Oncology Group (ECOG) scale of performance status, we used a twotailed independent proportion test to test the significance of the difference between any two sub-samples (groups). $p$ values less than 0.05 were considered statistically significant.

\section{Results}

The total number of surgical procedures undertaken was 457. Out of these, $365(80 \%)$ were a mix of complex, major and intermediate surgeries and 92 were minor procedures; 445 were elective cases, and 12 were emergency procedures. Median age of patient was 50 years with $347(76 \%)$ below 60. The median ASA class was I (I-IV), and ECOG performance score 0 (0-3). Patients of ASA I and II made up 97\% (443), and ECOG 0 and 1 were 92\% (421) (Table 1). The highest number of onco-procedures performed were head and neck surgery $(n 135 ; 29.5 \%)$ followed by GI surgery ( $n 106 ; 23.2 \%)$, gynaecology surgery 
Table 1 Patients demography, pre-operative status, surgical complexity and types of surgery

\begin{tabular}{|c|c|c|}
\hline Patient and surgical parameters & Number & $\%$ \\
\hline \multicolumn{3}{|l|}{$A S A^{*}$} \\
\hline 1 & 297 & 65 \\
\hline 2 & 146 & 32 \\
\hline 3 & 12 & 2.6 \\
\hline 4 & 2 & 0.4 \\
\hline \multicolumn{3}{|l|}{$E C O G^{* *}$} \\
\hline 0 & 247 & 54 \\
\hline 1 & 174 & 38 \\
\hline 2 & 30 & 7 \\
\hline 3 & 6 & 1 \\
\hline 4 & 0 & 0 \\
\hline \multicolumn{3}{|l|}{ Age in years } \\
\hline$<40$ & 118 & 26 \\
\hline $40-59$ & 229 & 50 \\
\hline $60-79$ & 105 & 23 \\
\hline$>80$ & 5 & 1 \\
\hline \multicolumn{3}{|l|}{ Number of cases based on surgical complexity } \\
\hline Complex & 194 & 43 \\
\hline Major & 116 & 25 \\
\hline Intermediate & 55 & 12 \\
\hline Minor & 92 & 20 \\
\hline \multicolumn{3}{|l|}{ Surgical cases types (based on site) } \\
\hline Head \& neck onco-surgery & 135 & 29.5 \\
\hline GI \& HPB*** oncology & 106 & 23.2 \\
\hline Gynae-oncology & 104 & 22.8 \\
\hline Breast oncology & 55 & 12 \\
\hline Uro-oncology & 26 & 5.7 \\
\hline Others & 31 & 6.8 \\
\hline Number of patients tested for Covid (Covid -ve) & 240 & 52.5 \\
\hline Number of patients requiring $\mathrm{ICU}^{\mathrm{a}}$ & 244 & 53.5 \\
\hline \multicolumn{3}{|l|}{ Post-op complications-Clavien-Dindo classification } \\
\hline 1 & 375 & 82 \\
\hline 2 & 78 & 17 \\
\hline 3 & 2 & 0.5 \\
\hline 4 & 0 & 0 \\
\hline 5 & 2 & 0.5 \\
\hline \multicolumn{3}{|l|}{$\operatorname{ICUS} S^{\mathrm{a}}($ days $)$} \\
\hline 1 & 152 & 62 \\
\hline 2 & 40 & 16 \\
\hline 3 & 25 & 10 \\
\hline$>3$ & 29 & 12 \\
\hline \multicolumn{3}{|l|}{$L O H S^{\mathrm{b}}$ (days) up to $5 / 5-10 / 10-15 />15$} \\
\hline 5 & 189 & 41 \\
\hline $5-10$ & 181 & 40 \\
\hline $10-15$ & 83 & 18 \\
\hline$>15$ & 4 & 1 \\
\hline Re-explorations & 02 & 0.44 \\
\hline
\end{tabular}

Table 1 (continued)

\begin{tabular}{lcr}
\hline Patient and surgical parameters & Number & $\%$ \\
\hline Mortality & 02 & 0.44 \\
\hline$A S A^{*}$ American Society of Anaesthesiologist, & $E C O G^{* *}$ & Eastern \\
Cooperative Oncology Group, GI \& $H P B^{* * *}$ gastrointestinal and \\
hepato-pancreato-biliary \\
$I C U S^{\mathrm{a}}$ intensive care unit stay, $L O H S^{\mathrm{b}}$ length of hospital stay
\end{tabular}

( $n 104 ; 22.8 \%)$ and breast surgery $(n 55 ; 12 \%)$. Cancer surgery in the miscellaneous group comprised excisions of squamous cell carcinoma and melanoma (/with lymph node dissections), soft tissue sarcoma (/with reconstruction) retro-peritoneal mass and amputations (/with reconstruction).

Out of total major cases of 365,112 (30.68\%) cases were taken up under regional anaesthesia. As a sole anaesthetic, it was administered in $46(44 \%)$ cases of gynae-oncology, $40(38 \%)$ cases of GI oncology, $13(50 \%)$ cases of urooncology and $15(48 \%)$ in miscellaneous group (Table 2).

In Table 3, details of site-specific cancer surgery-duration, blood loss and surgical complexity, ICUS and TLHS-have been shown. The overall mean and median values are compiled in Table 4. Post-operatively 119 patients were shifted towards from post-operative recovery on the same day. Rest 246 patients were kept in ICU, and $54(92 \%)$ patients needed ICU stay beyond 2 days. Postoperative Clavien-Dindo (CD) grade II complication requiring vasopressors and escalation of antibiotics was observed in 47 patients. Eighteen patients out of 110 (16.4\%) aged 60 years and above developed grade II CD complication compared to 61 out of $347(17.6 \%)$ patients below 60 years $(p=0.76)$. Ten percent of patients of ASA I developed grade II complication in comparison with $26 \%$ of ASA II $(p=0.00)$. Patients with ECOG grade 2 and 3 that developed grade II complication were $30.9 \%$ compared to $15.9 \%$ developed with ECOG 0 and 1. $(p=0.01)$ Grade $\geq$ III CD complication was encountered in $4(1 \%)$ patients. Two patients were grade III, one each of ASA III and IV. Both had ECOG performance score of 3. There were two re-explorations due to post-operative bleed and two post-operative deaths; there were no readmissions. The emergency surgeries included explorative laparotomies, colostomies for intestinal obstructions, re-explorations due to re-bleed, internal jugular vein blowout. Apart from surgeries, 57 non-operating room procedures were conducted- those included sedation for radiation, intrathecal chemotherapy, central venous line insertion, and Ryle's tube intubation in uncooperative patients that were carried 
Table 2 Anaesthesia in different surgeries

\begin{tabular}{|c|c|c|c|c|c|}
\hline \multirow{2}{*}{$\begin{array}{l}\text { Types of surgery (no) } \\
\text { Based on complexity }\end{array}$} & \multicolumn{4}{|c|}{ Types of anaesthesia (no) } & \multirow[t]{2}{*}{ Intubation avoided (\%) } \\
\hline & $\mathrm{GA}^{*}$ & $\mathrm{RA}^{* *}$ & $\mathrm{GA}+\mathrm{RA}$ & TIVA $^{\mathrm{a}} / \mathrm{MAC}^{\mathrm{b}}$ & \\
\hline Complex & 125 & 52 & 17 & 0 & 32.08 \\
\hline Major & 74 & 42 & 0 & 0 & \\
\hline Intermediate & 11 & 18 & 0 & $1 / 25$ & \\
\hline Minor & 01 & 02 & 0 & $12 / 77$ & \\
\hline Types of surgery (no) & \multicolumn{4}{|c|}{ Types of anaesthesia (no) } & Intubation avoided (\%) \\
\hline Based on cancer site & GA & $\mathrm{RA}$ & $\mathrm{GA}+\mathrm{RA}$ & TIVA/MAC & \\
\hline Head \& neck oncology & 74 & 0 & 0 & $0 / 61$ & 32.08 \\
\hline Breast & 41 & 0 & 0 & $0 / 14$ & \\
\hline GI \& HB oncology & 56 & 40 & 0 & $0 / 05$ & \\
\hline Gynae-oncology & 27 & 46 & 12 & $12 / 09$ & \\
\hline Uro-oncology & 06 & 13 & 01 & $01 / 04$ & \\
\hline Others & 07 & 15 & 0 & 0/09 & \\
\hline
\end{tabular}

Table 3 Intra-operative parameters and post-operative outcome based on cancer site

\begin{tabular}{|c|c|c|c|c|c|c|}
\hline $\begin{array}{l}\text { Type of cancer based on } \\
\text { site }\end{array}$ & $\begin{array}{l}\text { Blood loss } \\
(\mathrm{ml})^{*}\end{array}$ & $\begin{array}{l}\text { Duration of surgery } \\
(\min )^{*}\end{array}$ & $\begin{array}{l}\text { Grades of } \\
\text { surgery } \\
\text { complex/major } \\
\text { intermediate/ } \\
\text { minor }\end{array}$ & $\begin{array}{l}\text { ICUS** } \\
\text { (days) }\end{array}$ & $\begin{array}{l}\text { CD*** } \\
\text { complication } \\
1 / 2 / 3 / 4 / 5\end{array}$ & $\begin{array}{l}\text { LOHS }^{\mathrm{a}} \\
\text { (days) }\end{array}$ \\
\hline Head \& neck oncology & $\begin{array}{l}300 \\
\text { SD33 }\end{array}$ & $210 \mathrm{SD} 15$ & $45 / 8 / 43 / 39$ & $1(0-5)$ & $124 / 9 / 2 / 0 / 0$ & $10(1-15)$ \\
\hline GI\&HPB oncology & $\begin{array}{l}490 \\
\text { SD40 }\end{array}$ & $230 \mathrm{SD} 25$ & $55 / 37 / 12 / 2$ & $1(0-6)$ & $81 / 24 / 0 / 0 / 1$ & $10(2-17)$ \\
\hline Gynae-oncology & $\begin{array}{l}510 \\
\text { SD60 }\end{array}$ & $180 \mathrm{SD} 15$ & $66 / 9 / 6 / 23$ & $1(0-6)$ & $66 / 37 / 0 / 0 / 1$ & $8(1-15)$ \\
\hline Breast oncology & $\begin{array}{l}130 \\
\text { SD30 }\end{array}$ & $90 \mathrm{SD} 10$ & $1 / 38 / 2 / 14$ & $0(0-4)$ & $54 / 1 / 0 / 0 / 0$ & $5(3-10)$ \\
\hline Uro-oncology & $\begin{array}{l}490 \\
\text { SD70 }\end{array}$ & $240 \mathrm{SD} 20$ & $11 / 6 / 5 / 4$ & $1(0-5)$ & $22 / 4 / 0 / 0 / 0$ & $7(3-15)$ \\
\hline Others & $\begin{array}{l}200 \\
\text { SD30 }\end{array}$ & $120 \mathrm{SD} 10$ & $7 / 11 / 3 / 10$ & $0(0-4)$ & $30 / 1 / 0 / 0 / 0$ & $8(1-10)$ \\
\hline
\end{tabular}

Blood loss $(\mathrm{ml}) *$ and duration of surgery $(\mathrm{min}) *$-mean and standard deviation (SD)

ICUS** intensive care unit stay-median with range, $C D^{* * *}$ Clavien-Dindo grades of classification, $L O H S^{\mathrm{a}}$ length of hospital stay-median with range

out under sedation. Test for COVID-19 was undertaken in $240(52.5 \%)$ patients. Testing for Covid in our institute started on 24th April by RTPCR on permission obtained from the state although it was not implemented at the national guideline, to alleviate the fear factor amongst doctors and OT paramedics and to meet the demand of waiting list in forefront. None of the patients operated during this period were diagnosed with post-operative Covid. 
Table 4 Patients' parameters and related outcome (median with range, mean with $\mathrm{SD}$ )

\begin{tabular}{ll}
\hline Age (years) & $50(7-85)$ \\
ASA* class & I (I-IV) \\
ECOG** score & $0(0-3)$ \\
Blood loss (ml)—mean SD & 300 SD160 \\
Duration of surgery (min)—mean SD & 190 SD50 \\
ICUS ${ }^{\text {a }}$ (days) & $1(1-6)$ \\
LOHS $^{\text {b }}$ (days) & $7(1-17)$ \\
CD $^{* *}$ grade & I (I-V) \\
\hline
\end{tabular}

ASA* American Society of Anaesthesiologist, ECOG** Eastern Cooperative Oncology Group

$I C U S^{\mathrm{a}}$ intensive care unit stay, $L O H S^{\mathrm{b}}$ length of hospital stay, $C D^{* * *}$ Clavien-Dindo grade of classification

\section{Discussion}

The number of new cancer cases in India is more than 1 million as reported in Globocan [2]. In Odisha, death due to cancer is $72: 70(\mathrm{M} / \mathrm{F})$ and incidence is $72: 90(\mathrm{M} / \mathrm{F})$ per one lakh population and the mortality index ratio is 0.94 and 0.78 for males and females, respectively, which is higher than many states in India [3]. Hence, cancer treatment in our tertiary cancer hospital could not be ignored or avoided due to the COVID-19 pandemic. Surgery is the primary modality of treatment for most solid tumours of which breast, oral cavity and lip, cervix and uterus and stomach are the top five new cancers in India. Early surgery in these cancers offers cure [4]. However, surgical treatment of cancer makes the patient vulnerable to COVID-19 infection; major underlying reasons are prolonged perioperative stay in the hospital, compromised immunity, neoadjuvant therapy, close contact with healthcare personnel during surgery and post-operative ICU stay [5]. Disease spread from asymptomatic healthcare worker actively and closely involved in patient management was a major concern, and the reverse is equally likely to make the hospital staffs vulnerable to the infection [6]. Nonetheless, as many patients were already registered for surgery and most institutions offering cancer surgery were closed down, surgical outpatient department of our institution witnessed a high patient inflow. As the facility of Covid testing was not available initially, stringent screening procedure, identifying and deferring surgeries of patients from hot spot areas and universal standard precautions were put in place. As test in limited numbers became available, selected high-risk surgeries like head and neck and invasive procedures were subjected to testing till the facility was available at large for all oncology procedures.
As per our selection preference, median age of patient was 50 years. Although age above 60 years is a high risk, $24 \%$ of patient belonged to this age group. They were otherwise healthy and had comparable post-operative morbidity as that of the younger age group, and there were no deaths [7]. Ninety-seven percent of patients belonged to ASA I and II. Ninety-two percent of patients had good performance score of ECOG 0 and 1. Patients of ASA III who required surgery were put up based on their performance score and minimal or palliative surgical plan. This facilitated their post-operative outcome. Eight percent of patients had ECOG score 2 and 3 and mild post-operative complications. Patients of ASA IV and ECOG 3 were taken up only as emergency procedure and were managed successfully. We could not compare pre-operative physical status and performance score with CD grade $\geq$ III complication as the number was small to make statistical inference.

Regional anaesthesia (RA) is considered safer than general anaesthesia (GA) during the Covid pandemic [8]. Unlike normal circumstances, more number of gastrointestinal (GI) cases were administered RA instead of GA. In gynaecological oncology, only $27(26 \%)$ cases were intubated. Intubations in GA was undertaken with full precautions by crash induction and use of viral filter. Surgeries were carried out under full PPE. All standard protections for all aerosol generating procedures were followed.

Complex major surgeries of head and neck were myocutaneous flap reconstructions. Free flaps were avoided due to associated risks. Intubations of head and neck cancers that were anticipated to be difficult or required a bronchoscopic intubation were advised other non-surgical treatment modalities [9]. Difficult intubation due to previous surgery or radiation treatment was carried out by the experienced anaesthetists. All major surgeries were performed by a team that included a senior faculty and a junior surgeon or a senior student who have been involved in the workup of the patient.

Proper pre-operative selection of team, surgical plan and coordinated work and assistance facilitated a good outcome, short ICU stay and early recovery and discharge. This helped to minimise intraoperative blood loss and duration of surgical exposure. More than 60 percent were discharged from ICU/ post-operative ward, with one day stay, and almost 80 percent of our patients were discharged by the end of second day [10].

Our median length of hospital stay was seven days comparable with many other centres [11]. However, we witnessed a prolonged LOHS of 10 days and beyond in 87 (19\%) due to the lockdown. Despite all efforts, we could not shorten it further. Most patients coming for surgery to our centres are from remote places; they depend on public transport which was not available due to the lockdown 
[12]. Moreover, in the rarest possibility of a complication it should not go unattended.

There were various other obstacles we had to tackle. All investigations and testings were not available in the hospital, and patients needed to travel outsourced centres for this. Sanitisation, disinfection of hospital OPD, OT, laboratories and wards and other infection control measures needed lot of manpower and space which was our major constraint. Many patients and attendants are not educated; the practice of wearing mask, following respiratory etiquettes, hand hygiene and social distance were new to them. Ensuring adherence to these norms by the hospital administration was cumbersome and difficult. Our operation theatres lacked negative pressure and smoke evacuator system. WHO announced that increased infection of COVID-19 accounted for by healthcare workers [13]. Motivating the healthcare workers to work was an additional difficulty because they feared getting easily infected [14]. Safeguarding the health and well-being of junior doctors and staffs needed to be assured. Testing of all surgical staffs was not possible due to scarcity of testing. The working hours were curtailed, and the staff were allocated to work in turns. Although no patients were tested positive for Covid post-operatively nor any of the staff suffered from Covid symptoms, the presence of asymptomatic patients or healthcare worker could not be ruled out.

In spite of all constraints, surgery department 'continued to move forward' and provide service; our outcome was at par like normal situations. Encouraged by our modified and Covid-focussed protocols, we adopted this as our standard practice. Our initiatives opened up avenues for other centres in our region. After July 2020, when the ICMR guidelines were relaxed and more testing facilities were introduced including rapid antigen test (RAT), we started testing all patients requiring admission, surgery, radiotherapy and chemotherapy.

\section{Conclusions}

The obstacles in performing cancer surgery during Covid pandemic in our centres were many during the early period. Lack of in-house facility to perform the Covid test, availability of limited testing for COVID-19, and safe environment in OT were the ones that we faced at different stages of pandemic. We adopted measures, developed our own policy and provided surgical service catering to the demand to a large extent. This was a learning lesson for us on how to move forward and augment cancer surgery in our institute amidst a pandemic that would remain for an undetermined period with an unpredictable course.

Data Availability Available as and when required.

\section{Compliance with Ethical Standards}

Conflict of interest The authors declared that they have no conflict of interest.

\section{References}

1. Bhatla N, Singhal S. The COVID-19 pandemic and implications for gynaecologic cancer care. Indian $\mathrm{J}$ Gynecol Oncolog. 2020;18:48.

2. https://gco.iarc.fr/today/data/factsheets/populations/356-indiafact-sheets.pdf.

3. Dhillon PK, Mathur P, Nandakumar A, et al. The burden of cancers and their variations across the states of India: the global burden of disease study 1990-2016. Lancet Oncol. 2018;19:1289-306.

4. Bakos O, Lawson C, Rouleau S, et al. Combining surgery and immunotherapy: turning an immunosuppressive effect into a therapeutic opportunity. J Immunother Cancer. 2018;6:86.

5. Liang W, Guan W, Chen R. Cancer patients in SARS-CoV-2 infection: a nationwide analysis in China. Lancet Oncol. 2020;21(3):335-7.

6. Treibel TA, Manisty C, Burton M, et al. COVID-19: PCR screening of asymptomatic health-care workers at London hospital. Lancet. 2020;395(10237):1608-10.

7. Shrikhande SV, Pai PS, Bhandare MS, Bakshi G, Chaukar DA, Chaturvedi $\mathrm{P}$, et al. Outcomes of elective major cancer surgery during COVID 19 at Tata Memorial Centre: implications for cancer care policy. Ann Surg. 2020;272(3):e249-52.

8. Griffiths W, Pawa A. Regional anaesthesia and COVID-19: first choice at last? Br J Anaesth. 2020;125(3):243-7.

9. Deo SVS, Kumar S, Kumar N, et al. Guiding principles for cancer surgery during the COVID-19 pandemic. Indian J Surg Oncol. 2020;11(Suppl 1):1-8.

10. Colak E, Uyanik MS. Safe cancer surgery during the COVID-19 pandemic. Asian J Surg. 2020;43(7):786.

11. Ramachandra C, Sugoor P, Karjol U, et al. Outcomes of cancer surgery during the COVID-19 pandemic: preparedness to practising continuous cancer care [published online ahead of print, 2020 Oct 19]. Indian J Surg Oncol. 2020;1-5.

12. Sharma DC. Lockdown poses new challenges for cancer care in India. Lancet Oncol. 2020;21(7):884.

13. World Health Organization. Keep health workers safe to keep patients safe. Geneva: WHO; 2020.

14. Shaukat N, Ali DM, Razzak J. Physical and mental health impacts of COVID-19 on healthcare workers: a scoping review. Int J Emerg Med. 2020;13(1):40.

Publisher's Note Springer Nature remains neutral with regard to jurisdictional claims in published maps and institutional affiliations. 


\section{Authors and Affiliations}

\section{Rekha Das ${ }^{1}$ (1) Snigdha Rani Nahak ${ }^{2} \cdot$ Jita Parija $^{3} \cdot$ Prafulla K. Das $^{4} \cdot$ Lalatendu Sarangi $^{5} \cdot$ Padmalaya Devi $^{4}$. Pramod C. Pathy ${ }^{6}$}

$\triangle$ Rekha Das

rekhadas2003@yahoo.co.in

Snigdha Rani Nahak

drsnigdhan@yahoo.com

Jita Parija

jita049@gmail.com

Prafulla K. Das

pk.das12365@gmail.com

Lalatendu Sarangi

drlsarangi@gmail.com

Padmalaya Devi

padmalaya1@ rediffmail.com

Pramod C. Pathy

pramodchandra1965@gmail.com
1 Department of Anaesthesiology, AHPGIC, Cuttack, Odisha, India

2 Department of Pathology, AHPGIC, Cuttack, Odisha, India

3 Department of Gynaecological Oncology, AHPGIC, Cuttack, Odisha, India

4 Department of Surgical Oncology, AHPGIC, Cuttack, Odisha, India

5 AHPGIC, Cuttack, Odisha, India

6 Department of Head and Neck Oncology, AHPGIC, Cuttack, Odisha, India 